"This is the peer reviewed version of the following article: [Systems Research and Behavioral Science, 2020, 37, (5), pp. 804-812] which has been published in final form at [https://onlinelibrary.wiley.com/doi/abs/10.1002/sres.2743] purposes in accordance with Wiley Terms and Conditions for Self-Archiving." 


\section{A Design Science Research Approach to Closing the Gap between the Research and Practice of Project Scheduling}

Keywords: project scheduling, design science research, hybrid simulation, system dynamics, discrete event simulation.

\section{Jeff Scales}

University of Technology Sydney, Australia, Faculty of Design, Architecture and Building e-mail: jeff.scales@student.uts.edu.au

Keywords: project scheduling, design science research, hybrid simulation, system dynamics, discrete event simulation. 


\begin{abstract}
This paper illustrates one researcher's experience of applying Design Science Research (DSR) to the nexus between systems thinking and project scheduling. Project management has become increasingly popular in the decades since its advent but has changed little in that time. This is especially true is of its signature technique, project scheduling. Scheduling research however is vibrant and modern and even includes dynamic concepts such as learning curves in schedule construction. However, justifications for acquiring this level of systems literacy have not yet convinced the practice community. A similar gap is identified in management science and a literature review yields two potential solutions; dissolving the subjective-objective divide by adopting Critical Realism and using Design Science Research as a framework for producing artefacts. This paper outlines how these concepts were applied to project scheduling, resulting in a new method for schedule construction that allows an expanded range of concepts to be included.
\end{abstract}

\title{
Introduction
}

Since Gaddis hailed the advent of a new type of manager in the Harvard Business Review in 1959 the role of 'Project Manager' has become increasingly commonplace (Gaddis 1959, p. 59). The US-based Project Management Institute (PMI) for instance has grown from 24 founding members in 1968 to more than 500,000 in 2017, an annual compounding rate of over 22\% (PMI 2007, 2017b). The PMI's popular exam based credential scheme has matched this growth, rising from an initial 43 credential holders in 1986 to more than 823,000 in 2017, an annual compounding rate of over 37\% (PMI 2017b; Webster 1994).

The PMI's credential scheme is based on the content of their publication, A guide to the project management body of knowledge, commonly referred to as the PMBoK (PMI 2017a). Other such codified bodies of practitioner knowledge have been published in the UK (APM 2019), in Europe (IPMA 2017) and Japan (PMAJ 2005). These texts seek to define what a competent project manager should know and are based on research into the practice of project management, which has itself evolved as the popularity of project management has grown (Bredillet 2009; Turner, Pinto \& Bredillet 2011).

This self-referential process, where research into the practice of project management has been used to define what ought to be done, and taught to ever larger numbers of new practitioners, has been the subject of much criticism (Hällgren et al. 2012; Jacobsson \& Söderholm 2011) . Of particular concern is that this approach exposes both practitioners and researchers alike to what Hayek described as the "mechanical and uncritical application of habits of thought" where the future is defined in terms of what has been done in the past (Hayek 1952, p. 15).

The danger has not gone unnoticed with some researchers proposing to entirely rethink project management (Winter et al. 2006), to examine the constraints imposed by the largely positivist epistemological underpinning of much project management research (Smyth \& Morris 2007), and to question how the hard systems view prevalent in much of this research biases the way in which new research questions were framed (Pollack 2007; Williams 2005). Identifying and challenging these underlying assumptions, research through problematization, is seen as one way forward (Alvesson \& Sandberg 2011). 


\section{Project Scheduling}

Central to the practice of project management and perhaps its defining technique, is project scheduling. The most popular method for project scheduling is the Critical Path Method (CPM) which is espoused by all the codified bodies of knowledge and has not changed much since first publication (Kelley 1961). The PMI's Practice Standard for Scheduling (PMI 2011) distinguishes between scheduling methods, scheduling tools and the schedule model. Methods describe ways of constructing schedules (such as CPM), tools are usually software packages that embody the rules defining methods, and schedule models are created when methods are applied, using tools, to the specific data describing a project.

Project scheduling research has focused almost exclusively on methods, rather than tools or models. The Resource Constrained Project Scheduling Problem (RCPSP) is in the class of mathematical problems described as 'non-deterministic polynomial-time hard' because it is difficult to say beforehand how long a solution will take to calculate (Demeulemeester \& Herroelen 2002, pp. 203-5). The difficulty of the challenge has attracted significant interest (Hartmann \& Briskorn 2010), requiring the RCPSP research community to establish a common language, borrowed from mathematics, to efficiently describe the problem (Brucker et al. 1999; Herroelen, Demeulemeester \& De Reyck 2001). This intensely analytical approach however, has drawn criticism from within. Williams observed that much scheduling research "languishes in journals" rather than finding use in project practice (Williams 2003, p. 3) and Herroelen similarly observed that "many project scheduling procedures have not yet found their way to practical use" (Herroelen 2005, p. 413).

That research languishes in journals is evidence that a gap exists between the research and practice of scheduling. Scheduling methods supported by the tools that practitioners rely on, do not attempt to obtain mathematically exact or optimal solutions to the RCPSP, instead settling for computationally less intensive solutions using relatively simple rules called heuristics (Artigues \& Rivreau 2008; Demeulemeester \& Herroelen 2002, pp. 264-300). The simplicity of heuristics allows them to be applied to the large precedence networks that occur in practice, which would often result in unacceptable computing time if approached using an exact solution procedure. Heuristics based scheduling however, cannot guarantee an optimal solution. Results from scheduling tools popular with practitioners vary significantly in how closely they approach known optimal solutions, depending on the type of heuristic applied, whether more than one heuristic is used and the network and resource characteristics of the precedence network tested (Kastor \& Sirakoulis 2009; Trautmann \& Baumann 2009).

\section{Similarities to Issues in Management Science}

Similar concerns have been raised regarding the utility of the output of the much larger research community focused on management science. This has become known as the rigourrelevance debate, indicating that is it perceived as a mismatch of values between the research and practice communities (Huff \& Huff 2001; Starkey \& Madan 2001; Tranfield \& Starkey 1998). This debate remains ongoing (De Frutos-Belizón, Martín-Alcázar \& Sánchez-Gardey 2019) but two major ideas developed within it can be applied to the scheduling researchpractice gap. Both take a problematization approach by challenging basic assumptions.

The first idea is that the gap arises because the dominant philosophical paradigms, the empirical-analytical, the interpretive and the critical, when adopted individually simply do not accommodate the necessary range of concepts. They lack the requisite variety for a practical description of the world. Solving such a problem involves the adoption of a more 
accommodative philosophical framework with an expanded ontology. Within the rigourrelevance debate, Mingers has been a strong proponent of Critical Realism for this purpose (Mingers 2000, 2015). Critical Realism is a transcendental, realist, naturalist and critical philosophy of science. It is its strongly naturalist position that supports the expansion of project scheduling's ontology as Critical Realism argues that intangibles, such as morale, willingness to work, learning or fatigue are causally effective in the same way that physical structures are (Bhaskar 1979, 1993; Bhaskar \& Hartwig 2008). The real-world effects caused by these concepts are explained mechanistically through the action of generative mechanisms. These describe entities residing in the domain of the real, having power to create events in the domain of the actual, which may or may not be observed in the domain of the empirical. This stratified ontology, the empirical within the actual, within the real, is one of Critical Realism's defining elements (Bhaskar \& Hartwig 2008). The utility of explanatory mechanisms of this type has also been the subject of much discussion in the philosophy of science (Gerring 2007; Glennan 2002; Machamer 2004) for their ability to provide both physical and epistemic explanations for observed phenomena (Illari \& Williamson 2013; Illari \& Williamson 2011; Williamson 2013).

The second idea is that management science is much more like engineering or medicine than physics or chemistry, in that its artefacts are designed rather than discovered (Van Aken 2004) and its researches often involve abductive inquiry into systems that do not yet exist (Romme 2003). Solving such a problem involves bringing theoretical rigour to the design of new management artefacts or interventions. Design Science Research (DSR), as one such approach is called has been gaining acceptance in information technology (Kuechler \& Vaishnavi 2008, 2011, 2012) whilst still developing how theory and action are balanced effectively (Baskerville et al. 2018; Baskerville \& Pries-Heje 2019). The research community's acceptance of this approach is evidenced by the Journal of Operations Management recently having invited submissions using DSR as a strategy (Van Aken, Chandrasekaran \& Halman 2016).

\section{Methodology}

This research sought to apply these two findings to the project scheduling research-practice gap by using DSR as a strategy to operationalise the concept of ontological expansion. DSR has been described as the engineering approach to operations management, the core output of which should be a "well-tested, well-understood and well-documented innovative generic design that has been field tested to establish pragmatic validity" which would "enable practitioners to use it as a model for making case-specific designs." (Van Aken, Chandrasekaran \& Halman 2016, p. 1 \& 3).

One of the key aspects of DSR is that generic designs should be supported by design propositions, prescriptive statements about how existing knowledge is being used in the target context to generate the intended outcomes. Design propositions require the designer to take a systems view of their problem in focus, describing its context, what mechanisms generate the unwanted outcomes and how the intervention alters these circumstances to promote the wanted outcomes (Denyer, Tranfield \& van Aken 2008).

DSR prescribes a 5-step process. Step 1, awareness, describes the background to the problem, which should be both real-world and of interest to practice. Step 2, suggestion, draws on existing theories to describe generative mechanisms that have causal relationships to the problem. Step 3, development, is the design and realisation of this intervention, utilising the chosen technology and the design theories that have been developed for the 
effective use of that technology. Step 4, evaluation, is the empirical testing of the developed intervention, to ensure that the outcome has in fact been improved. Step 5, conclusion, assesses the generative mechanisms and design theories in light of the evaluation results (Kuechler \& Vaishnavi 2012).

\section{DSR Step 1, awareness of the project scheduling research-practice gap.}

Awareness of the problem is briefly described above, that research and practice in project scheduling have become disconnected and an increasing number of new practitioners are inducted every year into outdated ways of thinking.

\section{DSR Step 2, suggestion for closing the project scheduling research-practice gap.}

Suggestions for the expansion of scheduling's ontology have already been made. Williams advocated for the inclusion of intangibles (soft factors) to improve the relevance of scheduling research which has otherwise remained resolutely positivist (Williams 2003, p. 19). He drew support from Saaty and Forrester. Saaty wrote that operations research "would make a vast creative leap if it were to look seriously into models that handle intangibles and their measurement, because most of our problems deal with such factors" (Saaty 1998, p. 13). Forrester advised against "the omission of admittedly highly significant factors (most of the 'intangible' influences on decisions) because these are unmeasured or unmeasurable. To omit such variables is equivalent to saying they have zero effect ... probably the only value that is known to be wrong" (Forrester 1961, p. 57). One intangible concept, the learning curve, describing assimilation rates for new skills, has been sufficiently popular in the scheduling research community to prompt more than one state-of-the-art review (Azzouz, Ennigrou \& Ben Said 2017; Biskup 2008).

Such innovations have not made the transition into practice however, indicating that there are barriers to adoption. Archer's morphogenetic approach (Archer 2010) was employed to analyse the social structures conditioning the adoption of new developments in project scheduling. For the sake of brevity, only the outcomes of this analysis are presented here. The agencies, material structures, ideational structures and value-messages evident within the practice community are strongly biased towards morphostasis (a concept very similar to homeostasis). The key value-messages of professionalization (practice should be restricted to those qualified) and standardization (qualification should be based on a defined body of knowledge) espoused and controlled by the various professional bodies and the commercial apparatus of training and accreditation attached to these ideas create significant inertia. Any designed intervention must recognise these constraints.

The analysis prompted the adoption of 5 design propositions.

DP1. Familiarity; given the conservatism evident in the practitioner community, the designed artefact should look and act in as familiar a way as possible.

DP2. Mechanistic explanation; the designed artefact should explicitly show the cause-effect relationships relied upon to model intangibles, to allow practitioners to evaluate them using deductive logic.

DP3. Benchmarking; the designed artefact's capabilities should be validated using publicly available data, to allow for repeatability, replicability and modification of tests.

DP4. Relevance; the designed artefact should be capable of scheduling task networks and resource pools of the size and complexity commonly encountered in practice.

DP5. Open Source: the artefact should be designed and built using open source or readily available components, to lower the barriers to new researchers contributing to the published results. 


\section{DSR Step 3, development of a scheduling tool embodying the design propositions.}

Development proceeded by using the design propositions to guide and constrain decisions at the three different levels in Van Aken's design model (Van Aken 2004); process-design, realisation-design and artefact-design.

Process-design is the highest level of abstraction and is the framework for ensuring that the realised design has the capabilities to support the intended outcomes. The intended outcome of this research is a project scheduling tool that is capable of including generative mechanisms (soft factors, intangibles) in schedule construction. Its credibility as a scheduling tool is the first thing that needs to be established and the benchmarking design proposition (DP3) requires that this should be achieved using publicly available data.

Realisation-design involves the technical choices regarding building and implementing the design. The familiarity design proposition (DP1) seeks to avoid the shock of the new, so the design should accept standard scheduling data as input and produce Gantt charts as output. The relevance design proposition (DP4) seeks to avoid the most common criticism applied to research algorithms for scheduling, that they do not scale well to realistic network sizes. This requires the artefact to be designed for scalability in its chosen technology. The mechanistic explanation design proposition (DP2), seeks the clear exposition of cause-effect relationships in any generative mechanisms being modelled. Three further technical choices flow from this proposition. First is the adoption of system dynamics as the formalism to represent generative mechanisms. One of the fundamental principles of system dynamics, "the structure of the system gives rise to its behaviour" (Sterman 2000, p. 28) captures the essence of mechanistic explanation and its ontological and epistemological fit with Critical Realism has been well established (Lane 2001a, 2001b). Second is that choosing a calculus-based formalism requires a move to simulation modelling rather than the mathematics of algebra used by the majority of existing scheduling research. This move to continuous time mathematics also limits the design to heuristic methods for scheduling, which is not seen as a significant limitation given this is current practice. Lastly, having moved to simulation modelling, scheduling must now be accomplished in a way compatible with this sort of environment. Discrete Event Simulation (DES) can accomplish this (Lu 2003).

Artefact-design is the final level of abstraction where we consider how these design decisions will be implemented and any further constraints imposed by currently available technology. Employing both system dynamics and DES results in hybrid-simulation. The most popular commercial software package capable of hybrid simulation modelling for research is currently Anylogic, which uses the Java programing language (Brailsford et al. 2019). The guidelines for good laboratory practice in using modelling for research advise that the 'means' for other researchers to repeat or replicate results should also be provided (Kendall et al. 2016). This is understood to mean that the simulation model itself should be published, fulfilling the open source design proposition (DP5). Linking generative mechanisms, modelled in system dynamics, to DES based project scheduling however requires a novel design element. This novel element is needed to link task progress, modified by intangibles and mechanistically explained using system dynamics (Lyneis \& Ford 2007), to the scheduling of those tasks. This was achieved by modelling the work allocated to each resource assigned to a task as a stock of work to-do flowing through into a stock of work done, with the rate of this flow controlled by that individual resource's productivity. This makes productivity at the individual resource level a function that can be modulated by any concept the model builder wishes to model, see Figure 1 below. A more complete description 
of the technical details of the hybrid simulation model has been published previously (Scales 2019).

Figure 1 A system dynamics model of task progress

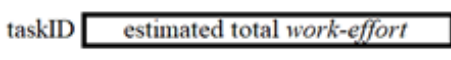

a) Standard Task Bar

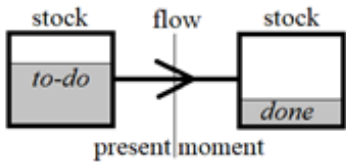

c) Two Stocks and a Flow

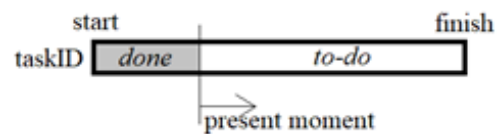

b) Representing Progress

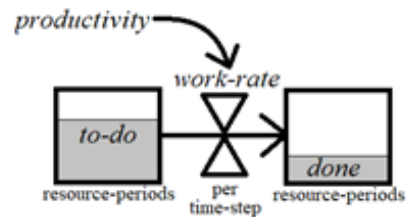

d) Productivity Controlling Work-Rate

\section{DSR Step 4, evaluation of whether the research-practice gap has been closed.}

Evaluation of a design is meant to assess whether the artefact or intervention has improved the intended outcome. The goal of closing the gap between the research and practice of project scheduling is an outcome that will take some time to assess. A more immediate evaluation however is possible by comparing the scheduling outcomes that the new approach generates against those produced by popular commercial scheduling tools using standard scheduling research test cases. A step back in scheduling capability would likely make the approach unviable. Following the benchmarking design proposition the test cases and comparison results should both be publicly available. The simulation model was evaluated against recent results for commercial software packages (Trautmann \& Baumann 2009) using standard test cases from the Project Scheduling Problem Library (Kolisch \& Sprecher 1997) which include benchmark results for optimal or best case solutions from literature (TUM 2020).

The simulation model was tested with unmodulated productivity to assess its baseline scheduling capabilities using the 30 task, 60 task and 120 task test cases $(n=1560)$ from the single-mode dataset (single-mode and multi-mode refer to differences in how resources are utilised). Trautmann and Baumann tested 7 seven commercially available packages, including the market leaders Microsoft Project (MSP) and Primavera Project Planner (PP6), using this dataset. They presented each test case to the software under test and recorded the overall duration of its scheduled solution, the makespan. For each result a difference was calculated between the best known makespan and that calculated by the software under test (the relative makespan deviation). This difference was then expressed as a percentage of the best known makespan (the relative makespan deviation \%). Simple statistical analyses (means and varances) were then performed on the accumulated results. Table 1 below compares the simulation model's results using this same approach for eight scheduling heuristics drawn from recent scheduling literature. The table compares them to Trautmann and Baumann's published results for the tests they made on the commercial package's best heuristic (or the default where this could not be changed). The best result achieved by the simulation model, using the CPM based heuristic of Minimum Late Finish (highlighted in bold), compares favourably with these results. A more complete description of the tests, measurements and analyses has been published previously (Scales 2019). 
Table 1 Benchmark testing results comparison

\begin{tabular}{|c|c|c|c|c|}
\hline \multirow[b]{2}{*}{ Heuristic } & PSPLIB Datasets & $\begin{array}{c}30 \\
\text { Tasks }\end{array}$ & $\begin{array}{c}60 \\
\text { Tasks }\end{array}$ & $\begin{array}{c}120 \\
\text { Tasks }\end{array}$ \\
\hline & & \multicolumn{3}{|c|}{ Mean Relative Makespan Deviation \% } \\
\hline \multirow{7}{*}{ 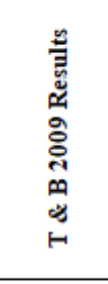 } & ACO best option & 3.66 & 4.64 & 11.78 \\
\hline & ATP default option & 5.67 & 5.72 & 12.55 \\
\hline & CSP best option & 3.31 & 5.46 & 14.68 \\
\hline & MSP default option & 5.18 & 6.51 & 15.19 \\
\hline & PP6 best option & 2.38 & 3.75 & 9.89 \\
\hline & PS8 default option & 4.93 & 5.25 & 12.26 \\
\hline & TPP best option & 8.61 & 9.92 & 24.42 \\
\hline \multirow{8}{*}{ 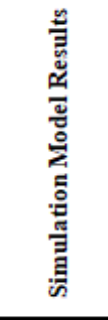 } & Min Total Float & 6.57 & 7.21 & 16.91 \\
\hline & Min Work Content & 10.69 & 12.14 & 26.67 \\
\hline & Max Work Content & 8.96 & 10.92 & 23.56 \\
\hline & Min Late Finish & 4.05 & 5.24 & 10.31 \\
\hline & Early Start & 8.17 & 9.62 & 20.31 \\
\hline & Min Duration & 9.83 & 11.12 & 23.79 \\
\hline & Min Free Float & 6.88 & 8.15 & 18.98 \\
\hline & Max Duration & 9.79 & 11.29 & 24.98 \\
\hline
\end{tabular}

\section{DSR Step 5, conclusion regarding the impact of the artefact.}

Conclusions, like evaluation results should ideally be drawn once the impact of the designed artefact can be properly appreciated and this research remains ongoing. However, the focus of this paper has largely been on the methodology employed, as one of two ideas abstracted from the rigour-relevance debate in management science. The first idea; that the continued influence of positivism leads to an inability to account for all relevant phenomena will be a familiar proposition to those in the systems research community. The second idea; Design Science Research may not be such a familiar proposition but has proved useful in this instance as a framework for making what might otherwise be seen as hard to justify creative decisions about how to move forward.

The DSR process begins with an awareness of a problem, some empirical anomaly or theory driven source of doubt, which drives the creative process of hypothesising the problem's source, described in generative mechanisms. The focus here has been on the evident gap between research and practice in project scheduling. The research community has long recognised that including intangibles in schedule construction would open up new avenues for improvement but has so far failed to realise any success in modifying practice.

For DRS's suggestion step this research turned to social realist theory to develop hypotheses regarding how the practice community's values and organisations create barriers to change, resulting in a number of guidelines for further action in the form of design propositions. Other theoretical lenses could have been utilised at this stage to develop potentially different hypotheses. These first two steps, awareness and suggestion, are abductive and other researchers may draw different conclusions from the same data but DSR allows the argument to be laid out (in extreme summary form here) for criticism.

DSR's development step operationalises the design propositions and develops further detail on how they constrain the choices that can be made, focusing on three levels of abstraction; process, realisation and artefact designs. The logical analysis of the constraints imposed by the design propositions allows the focus of the research to be delimited and circumscribed to a well-defined and justifiable solution; in this instance system dynamics for modelling 
intangibles, discrete event simulation for heuristic scheduling, combined within a hybrid simulation modelling environment.

DSR's evaluation step seeks to ensure that the problem identified in the awareness step and analysed in the suggestion step has in fact been improved by the output of the development step. This research benchmarked the simulation model results against published results for commercial scheduling software using publicly available and standardised test cases. The development and evaluation steps are deductive and (it is argued) flow logically from the design propositions. This clear separation between the abductive and deductive steps in the DSR process provides the researcher with a strong framework for ensuring that theoretical underpinnings are attended to before action is taken to test a hypothesis.

Lastly, the reflective step asks the researcher to question whether the outcomes achieved validate the chain of reasoning used to suggest and develop the design. This may result in a new awareness of the problem and a new round of investigation. The range of scheduling makespan results produced in this research for instance raises questions regarding why this is so. Then there is the question investigated by Baumann and Trautmann in 2016 regarding improvements in scheduling outcome when nesting heuristics (Baumann \& Trautmann 2016). Finally there is the question of how to move forward in testing the effect of intangibles on schedule outcomes when this is new research territory.

\section{Acknowledgements}

This research was supported by an Australian Government Research Training Program Scholarship. Supervisors; Prof. Shankar Sankaran, Dr Leila Moslemi Naeni.

\section{References}

Alvesson, M. \& Sandberg, J. 2011, 'Generating research questions through problematization', The Academy of Management Review, vol. 36, no. 2, pp. 247-71.

APM 2019, APM Body of Knowledge, 7th edn, Association of Project Management, Princes Risborough.

Archer, M.S. 2010, 'Routine, Reflexivity, and Realism', Sociological Theory, vol. 28, no. 3, pp. 272-303.

Artigues, C. \& Rivreau, D. 2008, 'Heuristics', Resource-constrained project scheduling: models, algorithms, extensions and applications, John Wiley \& Sons, pp. 87-105.

Azzouz, A., Ennigrou, M. \& Ben Said, L. 2017, 'Scheduling problems under learning effects: classification and cartography', International Journal of Production Research, pp. 120.

Baskerville, R., Baiyere, A., Gregor, S., Hevner, A. \& Rossi, M. 2018, 'Design Science Research Contributions: Finding a Balance between Artifact and Theory', Journal of the Association for Information Systems, vol. 19, no. 5, pp. 358-76.

Baskerville, R. \& Pries-Heje, J. 2019, 'Projectability in Design Science Research', Journal of Information Technology Theory and Application (JITTA), vol. 20, no. 1, p. 3.

Baumann, P. \& Trautmann, N. 2016, 'A note on the selection of priority rules in software packages for project management', Flexible Services and Manufacturing Journal, vol. 28, no. 4, pp. 694-702.

Bhaskar, R. 1979, The possibility of naturalism: A philosophical critique of the contemporary human sciences, Routledge.

Bhaskar, R. 1993, Dialectic: The Pulse of Freedom, Verso.

Bhaskar, R. \& Hartwig, M. 2008, A Realist Theory of Science, Routledge, London. 
Biskup, D. 2008, 'A state-of-the-art review on scheduling with learning effects', European Journal of Operational Research, vol. 188, no. 2, pp. 315-29.

Brailsford, S.C., Eldabi, T., Kunc, M., Mustafee, N. \& Osorio, A.F. 2019, 'Hybrid simulation modelling in operational research: A state-of-the-art review', European Journal of Operational Research, vol. 278, no. 3, pp. 721-37.

Bredillet, C.N. 2009, 'Mapping the dynamics of the project management field: Project management in action (part 4)', Project Management Journal, vol. 40, no. 4, pp. 2-5.

Brucker, P., Drexl, A., Möhring, R., Neumann, K. \& Pesch, E. 1999, 'Resource-constrained project scheduling: Notation, classification, models, and methods', European Journal of Operational Research, vol. 112, no. 1, pp. 3-41.

De Frutos-Belizón, J., Martín-Alcázar, F. \& Sánchez-Gardey, G. 2019, 'Reviewing the "Valley of Death" between management research and management practice: Towards a reorienting of paradigm assumptions in management science', Management Research Review.

Demeulemeester, E.L. \& Herroelen, W. 2002, Project Scheduling : A Research Handbook, Kluwer Academic Publishers, Secaucus, UNITED STATES.

Denyer, D., Tranfield, D. \& van Aken, J.E. 2008, 'Developing Design Propositions through Research Synthesis', Organization Studies, vol. 29, no. 3, pp. 393-413.

Forrester, J.W. 1961, Industrial dynamics, Pegasus Communications:, Waltham, MA.

Gaddis, P.O. 1959, 'The Project Manager', Harvard Business Review, vol. 37, no. 3, pp. 8997.

Gerring, J. 2007, 'The Mechanismic Worldview: Thinking Inside the Box', British Journal of Political Science, vol. 38, no. 1, pp. 161-79.

Glennan, S. 2002, 'Rethinking Mechanistic Explanation', Philosophy of Science, vol. 69, no. S3, pp. S342-S53.

Hällgren, M., Nilsson, A., Blomquist, T. \& Söderholm, A. 2012, 'Relevance lost! A critical review of project management standardisation', International Journal of Managing Projects in Business, vol. 5, no. 3, pp. 457-85.

Hartmann, S. \& Briskorn, D. 2010, 'A survey of variants and extensions of the resourceconstrained project scheduling problem', European Journal of Operational Research, vol. 207, no. 1, pp. 1-14.

Hayek, F.A.v. 1952, 'The Counter-Revolution of Science: Studies on the Abuse of Reason, Glencoe, Illinois', The Free Press.

Herroelen, W. 2005, 'Project Scheduling-Theory and Practice', Production \& Operations Management, vol. 14, no. 4, pp. 413-32.

Herroelen, W., Demeulemeester, E. \& De Reyck, B. 2001, 'A note on the paper "Resourceconstrained project scheduling: Notation, classification, models and methods" by Brucker et al', European Journal of Operational Research, vol. 128, no. 3, pp. 67988.

Huff, A.S. \& Huff, J.O. 2001, 'Re-Focusing the Business School Agenda', British Journal of Management, vol. 12, p. S49.

Illari, P. \& Williamson, J. 2013, 'In Defence of Activities', Journal for General Philosophy of Science, vol. 44, no. 1, pp. 69-83.

Illari, P.M. \& Williamson, J. 2011, 'Mechanisms are real and local', in P. Illari, F. Russo \& J. Williamson (eds), Causality in the sciences, Oxford University Press, Oxford, pp. 818 $-44$.

IPMA 2017, IPMA Certification Bodies, IPMA, viewed 22 June 2017, $<$ http://www.ipma.world/certification/certification-bodies/>. 
Jacobsson, M. \& Söderholm, A. 2011, 'Breaking out of the straitjacket of project research: in search of contribution', International Journal of Managing Projects in Business, vol. 4, no. 3, pp. 378-88.

Kastor, A. \& Sirakoulis, K. 2009, 'The effectiveness of resource levelling tools for Resource Constraint Project Scheduling Problem', International Journal of Project Management, vol. 27, no. 5, pp. 493-500.

Kelley, J.E.J. 1961, 'Critical Path Planning and Scheduling Mathematical Basis', Operations Research, vol. 9, no. 3, pp. 296-320.

Kendall, G., Bai, R., Błazewicz, J., De Causmaecker, P., Gendreau, M., John, R., Li, J., McCollum, B., Pesch, E., Qu, R., Sabar, N., Berghe, G.V. \& Yee, A. 2016, 'Good Laboratory Practice for optimization research', Journal of the Operational Research Society, vol. 67, no. 4, pp. 676-89.

Kolisch, R. \& Sprecher, A. 1997, 'PSPLIB - A project scheduling problem library: OR Software - ORSEP Operations Research Software Exchange Program', European Journal of Operational Research, vol. 96, no. 1, pp. 205-16.

Kuechler, B. \& Vaishnavi, V. 2008, 'On theory development in design science research: anatomy of a research project', European Journal of Information Systems, vol. 17, no. 5, pp. 489-504.

Kuechler, B. \& Vaishnavi, V. 2011, 'Promoting relevance in IS research: an informing system for design science research', Informing Science: the International Journal of an Emerging Transdiscipline, vol. 14, p. 125+.

Kuechler, B. \& Vaishnavi, V. 2012, 'A Framework for Theory Development in Design Science Research: Multiple Perspectives', Journal of the Association for Information Systems, vol. 13, no. 6, pp. 395-423.

Lane, D.C. 2001a, 'Rerum cognoscere causas: Part I - How do the ideas of system dynamics relate to traditional social theories and the voluntarism/determinism debate?', System Dynamics Review (Wiley), vol. 17, no. 2, pp. 97-118.

Lane, D.C. 2001b, 'Rerum cognoscere causas: Part II-Opportunities generated by the agency/structure debate and suggestions for clarifying the social theoretic position of system dynamics', System Dynamics Review (Wiley), vol. 17, no. 4, pp. 293-309.

Lu, M. 2003, 'Simplified Discrete-Event Simulation Approach for Construction Simulation', Journal of Construction Engineering and Management, vol. 129, no. 5, pp. 537-46.

Lyneis, J.M. \& Ford, D.N. 2007, 'System dynamics applied to project management: a survey, assessment, and directions for future research', System Dynamics Review, vol. 23, no. 2-3, pp. 157-89.

Machamer, P. 2004, 'Activities and Causation: The Metaphysics and Epistemology of Mechanisms', International Studies in the Philosophy of Science, vol. 18, no. 1, pp. 27-39.

Mingers, J. 2000, 'The Contribution of Critical Realism as an Underpinning Philosophy for OR/MS and Systems', The Journal of the Operational Research Society, vol. 51, no. 11, pp. 1256-70.

Mingers, J. 2015, 'Helping business schools engage with real problems: The contribution of critical realism and systems thinking', European Journal of Operational Research, vol. 242, no. 1, pp. 316-31.

PMAJ 2005, A Guidebook of Project \& Program Management for Enterprise Innovation, Project Management Association of Japan, Tokyo.

PMI 2007, PMI Annual Report

PMI 2011, Practice Standard for Scheduling - Second edition, Second edition. edn, Project Management Institute, Newtown Square, Pennsylvania. 
PMI 2017a, A guide to the project management body of knowledge (PMBOK® guide) - Sixth edition, Sixth edition. edn, Project Management Institute, Newtown Square, Pennsylvania.

PMI 2017b, PMI 2017 Annual Report, Project Management Institute, viewed 23 July 2019, $\langle$ https://www.pmi.org/annual-report-2017/at-a-glance>.

Pollack, J. 2007, 'The changing paradigms of project management', International Journal of Project Management, vol. 25, no. 3, pp. 266-74.

Romme, A.G.L. 2003, 'Making a Difference: Organization as Design', Organization Science, vol. 14 , no. 5, pp. 558-73.

Saaty, T.L. 1998, 'Reflections and projections on creativity in operations research and management science: A', Operations Research, vol. 46, no. 1, pp. 9-16.

Scales, J. 2019, 'Including Generative Mechanisms in Project scheduling using Hybrid Simulation', 63rd Annual Meeting of the International Society for the System Sciences, Corvalis.

Smyth, H.J. \& Morris, P.W.G. 2007, 'An epistemological evaluation of research into projects and their management: Methodological issues', International Journal of Project Management, vol. 25, no. 4, pp. 423-36.

Starkey, K. \& Madan, P. 2001, 'Bridging the Relevance Gap: Aligning Stakeholders in the Future of Management Research', British Journal of Management, vol. 12, pp. S3S26.

Sterman, J.D.J.D. 2000, Business dynamics: systems thinking and modeling for a complex world.

Tranfield, D. \& Starkey, K. 1998, 'The Nature, Social Organization and Promotion of Management Research: Towards Policy', British Journal of Management, vol. 9, no. 4, pp. 341-53.

Trautmann, N. \& Baumann, P. 2009, 'Resource-allocation capabilities of commercial project management software: An experimental analysis', Computers \& Industrial Engineering, 2009. CIE 2009. International Conference on, pp. 1143-8.

TUM 2020, Project Scheduling Problem Library - PSPLIB Technische Universität München, viewed 31 Jan 2020 2020, <http://www.om-db.wi.tum.de/psplib/>.

Turner, R., Pinto, J. \& Bredillet, C. 2011, 'The evolution of project management research: The evidence from the journals', The Oxford handbook of project management, Oxford University Press.

Van Aken, J.E. 2004, 'Management Research Based on the Paradigm of the Design Sciences: The Quest for Field-Tested and Grounded Technological Rules', Journal of Management Studies, vol. 41, no. 2, pp. 219-46.

Van Aken, J.E., Chandrasekaran, A. \& Halman, J. 2016, 'Conducting and publishing design science research: Inaugural essay of the design science department of the Journal of Operations Management', Journal of Operations Management, vol. 47-48, pp. 1-8.

Webster, F.M. 1994, 'Project management certification: the history', PM Network, vol. 8, no. 11, pp. 24-5.

Williams, T. 2003, 'The contribution of mathematical modelling to the practice of project management', IMA Journal of Management Mathematics, vol. 14, no. 1, pp. 3-30.

Williams, T. 2005, 'Assessing and moving on from the dominant project management discourse in the light of project overruns', IEEE Transactions on Engineering Management, vol. 52, no. 4, pp. 497-508.

Williamson, J. 2013, 'How Can Causal Explanations Explain?', Erkenntnis, vol. 78, no. 2, pp. 257-75. 
Winter, M., Smith, C., Morris, P. \& Cicmil, S. 2006, 'Directions for future research in project management: The main findings of a UK government-funded research network', International Journal of Project Management, vol. 24, no. 8, pp. 638-49. 